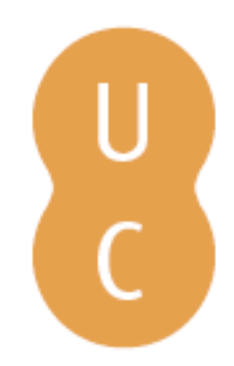

\title{
nombalina
}

\section{Carlos Jorge Pessoa, Escrita da Água: no rasto de Medeia}
Autor(es):
Marques, Susana Hora
Publicado por: Imprensa da Universidade de Coimbra; Annablume
URL
persistente:
URI:http://hdl.handle.net/10316.2/40909
DOI:
DOI:https://doi.org/10.14195/978-989-26-1298-0_3

Accessed : $\quad$ 26-Apr-2023 14:20:15

A navegação consulta e descarregamento dos títulos inseridos nas Bibliotecas Digitais UC Digitalis, UC Pombalina e UC Impactum, pressupõem a aceitação plena e sem reservas dos Termos e Condições de Uso destas Bibliotecas Digitais, disponíveis em https://digitalis.uc.pt/pt-pt/termos.

Conforme exposto nos referidos Termos e Condições de Uso, o descarregamento de títulos de acesso restrito requer uma licença válida de autorização devendo o utilizador aceder ao(s) documento(s) a partir de um endereço de IP da instituição detentora da supramencionada licença.

Ao utilizador é apenas permitido o descarregamento para uso pessoal, pelo que o emprego do(s) título(s) descarregado(s) para outro fim, designadamente comercial, carece de autorização do respetivo autor ou editor da obra.

Na medida em que todas as obras da UC Digitalis se encontram protegidas pelo Código do Direito de Autor e Direitos Conexos e demais legislação aplicável, toda a cópia, parcial ou total, deste documento, nos casos em que é legalmente admitida, deverá conter ou fazer-se acompanhar por este aviso.

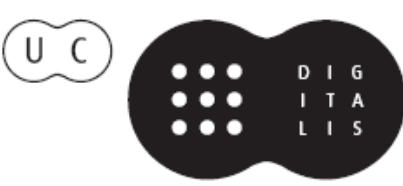




\section{O Livro do Tempo: \\ Escritas e reescritas}

\section{Teatro Greco-Latino e sua recepção II}

Maria de Fátima Silva, Maria do Céu

Fialho \& José Luís Brandão (coords.)

IMPRENSA DA UNIVERSIDADE DE COIMBRA 


\title{
Carlos Jorge Pessoa, Escrita da ÁGua: No Rasto de Medeia ${ }^{1}$ (Carlos Jorge Pessoa, Writing on water: Following Medea's steps)
}

\author{
Susana Hora Marques (smp@fl.uc.pt) \\ Universidade de Coimbra
}

\begin{abstract}
Resumo - Medeia, heroína de antanho, é convocada à cena contemporânea pela escrita de Carlos Jorge Pessoa, particularmente porquanto se associa de modo incontornável ao desmoronamento inesperado - e fatal - da família, um dos motivos fulcrais da peça Escrita da água: no rasto de Medeia. Revisitar Medeia implica para o autor destacar a dimensão humana e familiar da figura, que é inserida no contexto quotidiano do comum dos mortais da atualidade. Seguir no rasto da princesa colca é um pretexto para presentificar mitos civilizacionais representativos de valores intemporais, é um pretexto para questionar a família, núcleo restrito e primeiro de moldagem do ser, mas também as sociedades atuais.
\end{abstract}

Palavras chave - Carlos Jorge Pessoa, Medeia, reescrita.

Aвstract - Medea, the heroine of a bygone era, is summoned to the contemporary stage in the writings of Carlos Jorge Pessoa, in particular through the inexorable association to the sudden and fatal downfall of the family unit, one of the leitmotifs central to his play Escrita da água: no rasto de Medeia. The re-enactment of Medea required the author to highlight the human and familial aspects of the character which are inserted in the social context of modern daily life. To follow on the trail of the princess from Colchis is an alleged reason to present on stage societal myths that embrace timeless values whilst at the same time questioning the family as the restricted nucleus that primarely shapes human development but also the contemporary societies.

Keywords - Carlos Jorge Pessoa, Medea, rewritten.

\section{INTRODUÇÃo}

A tragédia que estamos a viver baseia-se em histórias de todos os dias que podem ser lidas nos jornais. Tenho aqui recortes, ei-los!...2

“Mãe atuou com 'especial perversidade' no caso das crianças de Caxias”; “menina de 5 anos que estava sozinha em casa morre após queda do $21^{\circ}$

${ }^{1} \mathrm{O}$ presente trabalho integra um texto mais amplo, em inglês, sobre a peça de Carlos Jorge Pessoa, incluído no volume II da coleção da Brill, que se encontra em fase de publicação e que é consagrado à receção do tema de Medeia em Portugal. Foi desenvolvido no âmbito do projeto UID/ELT/00196/2013, financiado pela FCT - Fundação para a Ciência e a Tecnologia. Deixo uma palavra especial de agradecimento a Maria João Vicente e a Carolina Mano, membros do Teatro da Garagem, pelas informações gentilmente concedidas.

${ }^{2}$ Escrita da água: no rasto de Medeia, 237. 
andar...”. Títulos como estes multiplicam-se na imprensa contemporânea, expondo reiteradamente a tragicidade da vida humana, hoje, ontem, sempre. Medeia, heroína de antanho, é convocada à cena pela escrita de Carlos Jorge Pessoa, diretor artístico e encenador do Teatro da Garagem ${ }^{4}$, particularmente porquanto se associa de modo incontornável ao desmoronamento inesperado - e fatal - da família, um dos motivos fulcrais da peça ${ }^{5}$. Revisitar Medeia implica para o autor destacar a dimensão humana e familiar da figura, que é inserida no contexto quotidiano do comum dos mortais da atualidade - por isso mesmo, no elenco das personagens, o nome 'Medeia', individualizador, é substituído pelo termo 'Mãe', capaz de irmanar a protagonista de outrora com a condição de tantas outras mulheres dos mais diversos tempos e lugares e, por outro lado, de evidenciar como as histórias se repetem. O facto de Escrita da água: no rasto de Medeia se contar entre os cinco textos complementares - mas independentes que integram o Pentateuco: manual de sobrevivência para o ano $2000^{6}$ espelha o desejo de uma conexão particular com o mundo coevo, porquanto este conjunto de produções aborda temas de relevo no Ocidente e no Portugal hodierno - 'a fé, a Europa, Portugal, a família, o futuro' 7 . A reunião das cinco peças sob um título comum traduz uma necessidade premente de reflexão, de debate, na iminência da chegada de um novo milénio, pelo que o projeto das representações do Teatro da Garagem previu, significativamente, um espetáculo de apresentação global dos cinco textos ${ }^{8}$, momento culminante de um percurso de dois anos em que cada peça foi sendo exibida per se em locais distintos. A inclusão da designação bíblica Pentateuco acentua a noção de uma sequência temática entre os textos, tal como acontecia com os cinco primeiros livros do Antigo Testamento, como se sabe, a propósito das origens do povo de Israel e da sua caminhada de libertação até à Terra Prometida, orientada por Moisés. A ideia de uma procura, de um percurso que urgia fazer-se em busca de nós próprios na última década do século XX, marcada por uma abundância e por um facilitismo aparentes, perpassa o Ciclo destas cinco peças escritas por Carlos Jorge Pessoa. Remetendo-nos para

${ }^{3}$ Notícias da imprensa portuguesa de 19 de fevereiro de 2016, respetivamente do Jornal de Notícias e do Diário de Notícias.

${ }^{4}$ Companhia de teatro fundada em 1989, conta com um autor/ encenador residente, Carlos Jorge Pessoa, e está no Teatro Taborda, em Lisboa, desde 2005.

${ }^{5}$ Representada pela primeira vez em 1998, no Teatro Rivoli, no Porto, esta peça teve diversas reposições em Portugal e no Brasil, nesse mesmo ano.

${ }^{6}$ Neste ciclo, com cinco peças originais de Carlos Jorge Pessoa, incluem-se os espetáculos O homem que ressuscitou: epifania em 20 estaçôes; Desertos: evento didáctico seguido de um poema grátis; Peregrinação: o fio de Ariadne; Escrita da água: no rasto de Medeia e A menina que foi avó: peça teatral em jeito de conto de fadas, todos eles levados à cena entre 1997-1998, ora separadamente, ora em conjunto.

7 "Programa do espetáculo", 22.

${ }^{8}$ Os 5 espetáculos do Pentateuco foram representados de modo sucessivo no Festival de Teatro de Montemor-o-Velho (CITEMOR), em julho de 1998. 
o passado, Pentateuco instiga ao estabelecimento de uma relação entre problemáticas que afetam diversas épocas - a História prossegue, incessantemente, retomando e reescrevendo personagens, comportamentos, situações, itinerários de vida. Nesse sentido de continuidade entre passado, presente e futuro, o título Escrita da água tão pouco parece isento de simbolismo: a água, elemento primordial que corre num fluir constante, é a imagem do fluxo ininterrupto que une a physis de diversas gerações, em todas as famílias e sociedades, água amniótica e água mortal, em simultâneo (cf. Escrita da Água, 277) ${ }^{9}$. Escrever na água volátil resulta em algo impreciso; seguir no rasto de Medeia, por sua vez, permite secundarizar os contornos da intriga tradicional e descentralizar a atenção da heroína à qual, todavia, se interliga a morte dos filhos, a tragédia familiar, ainda que em moldes bem distintos do original euripidiano, desta feita delineados pela perspetiva de Carlos Pessoa em relação à realidade ocidental e portuguesa contemporânea, pautada por uma crise de valores, de afetos, por uma crise da família, pela sobrevalorização do económico. Uma série de mortes com que o autor se deparou na vida pessoal marcou também o Manual de sobrevivência, porquanto o instigou a encontrar no teatro, palco de expressão de emoções e sentimentos, de questionamento, "um reduto de sobrevivência" ${ }^{10}$.

\section{ESCRITA DA ÁGUA - UM DIÁLOGO COM O TEMA TRÁGICO DE MEDEIA}

Que afinidades se percebem entre a Escrita da água e o tema 'Medeia'? Que significado tem para Carlos Pessoa convocar o mito da heroína colca à contemporaneidade? Desde logo, o facto de os textos clássicos ainda hoje fazerem sentido, favorecendo a abordagem de questões como a relação entre as pessoas, o poder, o amor, a morte. Por outro lado, a história trágica de Medeia permite refletir sobre a própria tragicidade da vida humana, tópico de relevo da versão contemporânea. Acresce ainda que, como em Eurípides, Medeia é esposa e mãe de uma família que a morte destrói - na Escrita da água, apenas o pai sobrevive, enlouquecido, bem como a sua memória do núcleo familiar de outrora: primeiro morrera a esposa, numa banal intervenção cirúrgica, e em seguida os dois filhos, um menino e uma menina, na piscina do hotel onde passavam férias para procurar esquecer a perda da mãe. A traição do marido, por sua vez, designado genericamente, no texto de 1998, como 'Pai', é mais um motivo que aproxima a peça portuguesa da versão clássica euripidiana, ainda que agora não

\footnotetext{
${ }^{9} \mathrm{Cf}$. a conceção de Heraclito sobre a realidade, entendida como um fluir contínuo (cf. fr. 12 Diels-Kranz).

${ }^{10}$ Afirmações de Carlos Jorge Pessoa em entrevista a Fernando Matos Oliveira e Mickael de Oliveira, em 2014. Disponível em http://ww3.fl.ul.pt/centros_invst/teatro/pagina/ Publicacoes/artigos2008/MJB_caminhos_da_escrita_dramatica_em.htm [consultado a 22 de janeiro de 2016].
} 
se apontem motivos políticos que procurem justificar essa traição. Tão pouco a esposa mal-amada busca estratagemas para se vingar das relações extraconjugais do companheiro, embora tenha conhecimento das mesmas - simbolizará a sua atitude o conformismo - e o cansaço - de algumas mulheres/ mães de família modernas, que sobrevalorizam o papel social de mãe/ pai, a salvaguarda das aparências, em detrimento da vida amorosa do casal? A Amiga, uma das personagens que se inclui no novo elenco, evoca precisamente a figura de uma rival de Medeia, qual Creúsa/ Glauce da Antiguidade; numa produção que coloca em cena vivos e mortos em diálogo, garantindo teatralidade à peça e também motivo de questionamento, a Mãe, já morta, dirige-se à Amiga, sem rancores percetíveis, nos expressivos termos que se seguem: "Eu sei, eu sempre soube que amavas o paizinho..." (Escrita da água, 263). Constituindo-se como uma das três personagens da ficção cinematográfica que se produz dentro do próprio espetáculo teatral, a par do Homem do Cinema e da Voz Off (= Realizador) ${ }^{11}$, a figura da Amiga, uma atriz na película que está em rodagem para gravar - e recordar - aquela tragédia familiar ${ }^{12}$ ("Sou uma amiga que testemunhou alguns momentos decisivos desta história”, Escrita da água, 232), remete para um dos elementos do triângulo amoroso da tradição clássica do mito, permitindo estabelecer o diálogo entre tempos e artes distintas, o passado e o presente, o teatro e o cinema, entrecruzamento sugestivo da repetição de situações, de forma ininterrupta, que afetam o ser humano em geral, independentemente do seu estatuto social, do país, da época em que se situa. Nesse sentido, o diálogo é uma forma de expressão por excelência da Escrita da água.

Paradigmático da desagregação familiar, o mito de Medeia presta-se pois a uma visão da crise que atinge boa parte das famílias nas sociedades ocidentais contemporâneas - é natural, por isso, que, ao contrário do modelo euripidiano, a nova Medeia não se revista da grandeza da princesa bárbara de antanho, mas surja em vez disso como uma mulher comum, enquadrada na banalidade do mundo ocidental hodierno, marcada pela perda de liames familiares.

Os ecos da tragédia clássica são ainda percetíveis nas palavras de abertura do espetáculo apresentado pelo Teatro da Garagem, que constituem uma

${ }^{11}$ A ideia de converter o Homem do Cinema e o Realizador em personagens da cena recorda o que fizeram Anouilh e também o português António Pedro a propósito de Antígona, na linha de Pirandello (cf. capítulos de M. F. Silva e de C. Morais, no volume I da coleção Brill (no prelo), relativos a Anouilh e a António Pedro, respetivamente) - trata-se de uma tática de exploração metateatral que dá voz a figuras transteatrais, permitindo-lhes fornecer indicações técnicas, mas também ir comentando o que se passa em palco e, desse modo, entrecruzar ilusão e realidade, passado e presente.

${ }^{12}$ Cf. capítulo de M. F. Silva e M. H. Hörster no volume II da Coleção Brill (em fase de publicação), relativo à Medeia de Mário Cláudio, onde se fala de uma atriz que toda a vida sonhou fazer o papel de Medeia, procurando a compreensão da heroína euripidiana e da sua própria vida. 
espécie de prólogo proferido pela única intervenção na peça de um Coro de dois elementos - numa tonalidade prenunciadora de tragédia, esboçam-se temas de relevo retomados em seguida pela cena, nomeadamente os da fragilidade da vida humana, da inevitabilidade do destino, da ingenuidade e inocência infantis, da morte.

Carlos Jorge Pessoa, no entanto, para refletir sobre «a natureza do sentimento trágico da vida»', apenas pretende seguir 'no rasto de Medeia', pelo que opções diversas, a nível temático e formal, sublinham a distância entre a versão euripidiana e a deste autor, que ganhará sentidos com um conhecimento prévio do texto do século $\mathrm{V}$ a.C.

"O rasto de Medeia representa uma espécie de negativo do retrato clássico; nesta peça, a mãe e os filhos são espíritos cujo verbo inspira os vivos a retomarem a vida < como se perceberá $>$ "14.

Os propósitos de Carlos Pessoa levam-no desde logo a alterar a listagem inicial das personagens, que concede papel preponderante à família em geral, omitindo os nomes próprios de cada um dos seus quatro elementos e registando, em vez deles, os termos 'Mãe', 'Pai', 'Criança 1', 'Criança 2', sugestivos de que a tragédia familiar que o texto recorda é apenas exemplo de mais "um caso entre tantos outros" (Escrita da água, 246), desestabilizador de qualquer núcleo familiar. Incitam-no também a incluir no elenco, para além da Amiga, figuras que remetem para o seu gosto pessoal pelo cinema e que conferem traços da modernidade a teatro antigo - o Homem do Cinema e a Voz Off, como ficou dito. O Homem do Cinema em particular, para além das indicações técnicas que vai dando a propósito da filmagem, tece comentários à história trágica da família que o filme evoca e estabelece relações com a sua própria história de vida, sobre a qual vai refletindo, em intervenções que recordam o Coro da tragédia clássica, como por exemplo: "Mas afinal quem foram eles? Quem somos nós? Qual a sua diferença? Qual a nossa diferença? Estará a diferença apenas no destino? Seremos apenas marionetas do destino?” (Escrita da água, 238). Neste confronto entre passado e presente, favorecido pelas vozes do Homem do Cinema e também da Amiga, figuras que complementam o papel habitual do Coro, a perceção de forças superiores que parecem comandar de modo contínuo a vontade humana sublinha a noção da fragilidade existencial. $\mathrm{O}$ texto, escrito em prosa, distribui-se por quatro quadros, precedidos pela espécie de prólogo inicial já mencionada e subdivididos em várias cenas separadas pela claquete, nas quais se inclui um epílogo. Sugestivos dos episódios da tragédia clássica, esses quadros, porém, mais do que no desenvolvimento de uma intriga específica, centram-se na reflexão que se produz na contemporaneidade a partir da história

\footnotetext{
${ }^{13}$ Programa do espetáculo, 6 .

${ }^{14}$ Programa do espetáculo, 6.
} 
trágica de uma família cujos membros as filmagens trazem à cena (cf. e.g. as palavras da Amiga: "são as crianças que vão morrer, será que não entendem como é terrível, e horrível (...)? Como podem morrer, com dois erres, as crianças, duas, como podem ser sacrificadas, repito, com r, sacrificadas, os inocentes, oh deuses, porquê?" - Escrita da água, 256). Palavras/ expressões da linguagem cinematográfica mesclam-se, naturalmente, com o discurso teatral (cf. e. g. 'zoom' (Escrita da água, 248), 'acção!'; 'Repete, mais pathos...' (Escrita da água, 250), 'uma panorâmica geral!' (Escrita da água, 265)). A diferença entre a criação de Carlos Pessoa e a tragédia clássica que lhe serve de modelo é assinalada por fraturas evidentes em relação a elementos tradicionais: assim, por exemplo, o estatuto nobre - e excecional - característico das personagens da tragédia clássica, bem como as situações extremas por elas vividas ou a solenidade da linguagem em que se expressam, tudo se altera em nome do enquadramento da produção num contexto compatível com a realidade do homem comum contemporâneo.

\section{FAMÍlIA: UM TÓPICO DE RELEVO DA VERSÃo CONTEMPORÂNEA}

As palavras de Carlos Jorge Pessoa, no programa do espetáculo (pp. 6-7), são expressivas da reflexão que o autor propõe para a Escrita da água, no que ao tema 'família' diz respeito:

A família é entendida como célula agregadora em crise, crise de afectos, crise de valores, despoletada pelo acontecimento trágico; a questão principal tem a ver com duas posições distintas: ser fiel à memória e abstermo-nos da vida no sentido de abdicarmos da mesma, enveredando por um luto perene, ou a lealdade à memória, que não ignorando o passado o reescreve numa nova oportunidade, numa vida renovada, renascida. O objectivo da peça passa por uma reinvenção da Família, e esta constitui uma unidade possível de um processo de transformação social mais vasto, um processo em que a Cidade se revê, se rearticula. A Família na tragédia clássica é sempre o mote exemplar para uma reflexão mais ampla; neste aspecto fomos razoavelmente conservadores.

A família, célula primeira que nos influencia, é um ponto de partida para uma meditação mais ampla, relacionada com as nossas sociedades ocidentais sob o olhar de Carlos Pessoa, o mito de Medeia espelha sobretudo a história de uma família contemporânea comum, constituída por uma Mãe, um Pai e duas Crianças, que se desmorona devido a uma tragédia súbita. Num mundo marcado pela perda de valores, pela decadência da noção de família, é importante refletir sobre laços que a morte quebra, incomodando os vivos (cf. Escrita da água, 269). A família, centro de afetos, de segurança, de proteção, é também lugar de libertação, de respeito pelas diferenças, pelas inquietações individuais, "um lugar sinónimo de cidadania" (Pai, Escrita da água, 238), onde cada elemento 
tem voz. O seu desmantelamento, com a negra morte por comandante, sem aviso prévio e sem escolha de idades ou classes sociais, destabiliza, desespera, enlouquece. Por isso o Pai anda à deriva, na peça de 1998, sedento das afeições e dos liames de outrora, dominado por uma saudade que materializa no vestido de noiva com que aparece em cena e que lhe traz à memória a companheira e a vida passada: "sou um fraco, sem força anímica para controlar o desespero; limito-me a enlouquecer" (Escrita da água, 237). Os ecos do mito de Medeia nesta personagem dos nossos dias percebem-se em aspetos como o desmoronamento da sua família, com a morte a atingir os próprios filhos, ou como a sua traição da relação conjugal - o resto é desvio, mesmo a forma como dialoga com a esposa morta: um tom carinhoso substitui-se à retórica do modelo euripidiano, porquanto a afetividade, a importância dos laços familiares são precisamente questões que agora se pretende destacar. A solidão e o sofrimento que o Pai vive, após as mortes dos seus, favorece uma série de considerações sobre o que fora a sua existência no papel de homem de família no Portugal coevo - e no ocidente em geral -, realidades que não deixa de criticar:

A família, o emprego, o prestígio, a casa... eram essas as preocupações que dominavam a minha cabeça e no entanto sabia que faltava alguma coisa (...); neste mundo controlado, vigiado, eu tinha que inventar um lugar! (...)...eu sentia a teia de poderes que dominam o mundo, eu percebia como a individualidade se desvanece nessa teia (...). A minha família teria o seu lugar, um lugar que fosse sinónimo de libertação, sinónimo de respeito pelas nossas diferenças, pelas nossas inquietações, sinónimo de cidadania (Escrita da água, 237-238).

(...) ... a minha lista de contactos é maior que um rolo de máquina registadora, isso é fundamental para uma pessoa que queira vencer na vida... (Escrita da água, 252)

Integrando a sua atuação nos padrões de um pai de família comum, era dominado por preocupações habituais do homem contemporâneo, ainda que sentisse desajuste entre as exigências sociais e a singularidade que distingue cada família. As atitudes do Pai no post-mortem da família parecem convergir para uma 'abstenção da vida': “- Ajudem-me a dar um tiro" (Escrita da água, 236), pede, num grito expressivo da sua falta de perspetiva existencial.

A importância concedida pela peça à dimensão familiar fomenta a recriação de cenas passadas no domínio da vida privada, sugestivas de sentimentos e emoções com que se vão entretecendo as relações humanas. Na verdade, o Pai evoca o carinho e a paciência com que assobiava canções de embalar para os seus bebés, imprescindíveis na hora de os adormecer (cf. Escrita da água, 261). De modo significativo, alerta também para a fragilidade dos pequenos seres (Escrita da 
água, 262), que é preciso proteger. Por outro lado, confessa reiteradamente a sua afeição pela esposa já sem vida, numa insistência ilustrativa da saudade suscitada pela ausência física (cf. Escrita da água, 276) e, em particular, da valorização que o ser humano confere em geral àqueles que perde.

O retrato de família complementa-se com a perspetiva da Mãe, uma voz que instiga os vivos a prosseguirem a existência, a recomeçarem, apesar da memória da tragédia, apesar do desagregar da família. Na verdade, dirigindo-se à Amiga e ao Pai, num discurso sugestivo de que a infidelidade do companheiro é uma característica que se preserva no texto de Carlos Pessoa, como foi dito, afirma: “...oxalá sejam felizes os dois... (...) Vá lá, dêem as mãos, isso, assim é que vos quero ver, de mãos dadas!” (Escrita da água, 263). As suas intervenções descrevem como vivera a condição de esposa e de mãe, sem dúvida papéis destacados pela peça de 1998. Curiosamente, embora desta feita se sublinhe a vertente amorosa e familiar de Medeia, há uma ou outra intervenção da personagem que parece aludir a traços da heroína clássica, nomeadamente ao seu carácter descontrolado, que se apressa a conter (cf. Escrita da água, 266, 270), bem como à circunstância de esposa traída, mal-amada (cf. Escrita da água, 267). No entanto, perpassa sobretudo a imagem de uma Mãe ternurenta, respeitada (cf. "os meus pintainhos" (Escrita da água, 264) / "Minha Menina (...), encho o teu corpo de beijos" (Escrita da água, 265)/ "Eu quero-vos bem, meus filhos" (Escrita da água, 275)), inusitadamente tímida, de uma Mãe cansada, que suportou quase tudo sozinha - "dizem que as mães são a força estruturante" (Escrita da água, 266). Inserindo a sua atuação nos padrões da sociedade envolvente, educara os filhos da melhor forma que pudera: "a melhor alimentação, vestir, calçar, os melhores colégios (...) ...'melhor' era o que eu acreditava que valia a pena, que era seguro...(...) ...eu lutei por essa ordem que me parecia justa, fui pragmática, uma mãe pragmática" (Escrita da água, 271).

A nível da relação do casal, ainda que a Mãe não poupe críticas ao companheiro do passado, senhor de múltiplos uniformes - de marido, de amante e de homem (cf. Escrita da água, 267) -, recorda, em diálogo com ele, o encontro de antanho entre os dois, a paixão, o entusiasmo, num cenário muito atual e 'de passagem' - o telheiro de uma bomba de gasolina junto à estação de comboios (Escrita da água, 278) ${ }^{15}$.

Da relação entre a Mãe e o Pai resultaram duas crianças, filhos que Medeia não mata, ao contrário da heroína euripidiana, ainda que não deixe de ser, em certo sentido, por causa da progenitora que os filhos morrem - as férias, a piscina representam uma forma de procurar esquecer um pouco a perda da mãe. Recordemos que ser filho de Medeia, com toda a tradição que isso implica,

${ }^{15}$ Este tópico do amor fulminante, que tudo condiciona, é parte do motivo de Medeia na Cólquida, como se sabe. 
exige um desfecho específico para as crianças: a morte. A presença do menino e da menina em cena permite evocar o universo infantil, significativo numa produção que valoriza a família; permite igualmente destacar o poder de juntar sílabas, de formar palavras, de construir sentidos, como as crianças. O teatro, palco de reflexão, questiona a razão da morte terrível de dois meninos inocentes (cf. Escrita da água, 256); não há respostas, porém; apenas a "vontade de entender o sentido da vida" (Homem do Cinema, Escrita da água, 257). Para as crianças, viver faz sentido, pelo que as suas palavras podem de algum modo ser entendidas como um estímulo para um recomeço, para um futuro (cf. Escrita da água, 273):

O meu vocabulário não pára de crescer, cada dia que passa acrescento novas palavras, cada uma com significados diferentes... antes de adormecer repito em voz alta cada palavra e delicio-me com o som de cada sílaba, com o modo como os sons se procuram, se fundem...

Trazer à cena esta tragédia familiar na ficção fílmica em rodagem no próprio espetáculo permite também ao Homem do Cinema recordar, de passagem, a sua progenitora de outrora, porto de abrigo em momentos de tristeza (cf. Escrita da água, 235), mas a quem uma doença arrebatara a vida. Uma fotografia da mãe, que guarda, torna-a presente (cf. Escrita da água, 236), mas evidencia também que ele se converteu num "fragmento sem unidade" (Escrita da água, 236), numa peça solitária - e sem sentido - da família, da sociedade. "Não me apetece arranjar soluções” (Escrita da água, 247) ou “...no fundo, quero aprender a morrer convosco..." (Escrita da água, 265), ou ainda "ensina-me a morrer... sinto uma enorme descrença em tudo isto" (Escrita da água, 271) são desabafos que parecem apontar para uma 'abstenção da vida' por parte de um homem do nosso tempo, angustiado pelo peso da memória. Viver com a memória, no entanto, não é impeditivo de recomeçar um novo ciclo, de renascer para uma existência renovada. No epílogo da peça, as palavras do Homem do Cinema, resultantes de uma reflexão que vai partilhando com a cena e com o público, aludem à tragédia como "derradeiro testemunho de esperança".

O sentido trágico da vida talvez nos enobreça, porque não nos alimenta a vaidade; porque nos torna humildes: não, não se trata de rendição, mas antes de combate (...). A tragédia talvez seja um testemunho da nossa necessidade irreprimível de amarmos a vida em toda a sua plenitude. (Escrita da água, 284-285)

\section{Conclusão}

Seguir no rasto de Medeia é um pretexto para presentificar mitos civilizacionais representativos de valores intemporais, é um pretexto para questionar 
a família, núcleo restrito e primeiro de moldagem do ser, mas também as sociedades atuais, dominadas por perspetivas economicistas, consumistas, em que o individualismo se sobrepõe a valores humanos tradicionais. Num mundo em crise, a memória da tragédia é mote de reflexão que poderá abrir caminho para uma reconstrução do nosso universo, ainda que sem esquecer o passado. As linhas gerais do mito de Medeia não são desenvolvidas pela peça de Carlos Pessoa, que retoma sobretudo um nome em estreita associação com a tragédia antiga - Medeia -, alguns motivos da história da heroína de outrora - a condição de mulher e mãe, a morte dos filhos por causa da progenitora (mas não por ela), a inocência das crianças, a infidelidade do marido -, e ainda temas conectados com este mito, como o da fragilidade da vida humana ou o do desmoronar da família. A peça contemporânea segue apenas 'no rasto' de Medeia, suavizando-lhe os traços cruéis de outrora, porquanto é a relação familiar, física e dolorosamente quebrada pela morte inesperada, que se destaca - falam pais e filhos, reunindo as gerações no diálogo. Perdura a água, a renovar continuamente a physis humana. 


\section{Bibliografia}

Brilhante, Maria João (2003), "Caminhos da escrita dramática em Portugal no final do século XX”, Lisboa. Disponível em http://ww3.fl.ul.pt/ centros_invst/teatro/pagina/Publicacoes/artigos2008/MJB_caminhos_ da_escrita_dramatica_em.htm [consulta a 20 de dezembro de 2015]

Camacho Rojo, J. M. (ed.) (2006), La tradición clásica en la obra de Federico García Lorca. Granada, Universidad de Granada.

Entrevista de Fernando Matos Oliveira e Mickael de Oliveira a Carlos Jorge Pessoa, no âmbito do Centro de Dramaturgia Contemporânea (2014). Disponível em http://www.uc.pt/org/centrodramaturgia/4/pqrs/pessoa_ carlos_jorge [consulta a 22 de janeiro de 2016]

Floeck, Wilfried (1997), "El teatro actual en España y Portugal", Discursos: Estudos de Lingua e Cultura Portuguesa 14: 47-67.

Nogueira, Joaquim Paulo (2002), “Escribir lo real”, in J. Monleón y N. Diago, Teatro y realidade - Acción teatral de la Valldigna II. Valência, Universitat de Valência: 93-100.

Pessoa, C. J. (1998), Pentateuco: Manual de sobrevivência para o ano 2000. Lisboa, Cotovia.

Serôdio, Maria Helena (1997), "Teatro portugués actual. Un dossier sobre el teatro en Portugal", ADE Teatro 62-63: 55-101.

Silva, M. F. S., coord. (2006), Furor: ensaios sobre a obra dramática de Hélia Correia. Coimbra, Imprensa da Universidade de Coimbra. 